\title{
KETERAMPILAN MENJAHIT BAGI ANAK PANTI ASUHAN RUMAH YATIM DI KOTA BANDAR LAMPUNG
}

\author{
Ochi Marshella Febriani, ${ }^{1}$ Dona Yuliawati, ${ }^{1}$ dan Delli Maria ${ }^{2}$ \\ 'Jurusan Sistem Informasi, Institut Informatika dan Bisnis Darmajaya, Bandar Lampung, Indonesia \\ ${ }^{2}$ Jurusan Akuntansi, Institut Informatika Dan Bisnis Darmajaya, Bandar Lampung, Indonesia \\ E-mail: ochimarshella@darmajaya.ac.id
}

\begin{abstract}
ABSTRAK. Permasalah yang dimiliki Panti Asuhan Rumah Yatim Aarohman cabang Lampung secara umum sama dengan panti asuhan lainnya yaitu pertama, persoalan utama yang ditemukan pada anak-anak seperti adik-adik di panti asuhan ini adalah rasa minder dan adanya mental blocking, bahwa mereka adalah orang yang malang dan tidak bisa sesukses seperti orang lain. Persepsi ini dapat membuat anak gagal dalam berkompetisi dengan dunia luar. Kedua, Anak Yatim saat ini hanya mengenyam pendidikan Formal, yang masih minim mengajarkan keterampilan. Keterampilan tehnis yang bisa menjadi bekal anak yatim dalam mencukupi kebutuhan hidup kedepannya. Misalnya keterampilan menjahit dan membuat pelengkapan berbahan perca kain. diberi dan dibimbing motivasi untuk mempelajari sesuatu yang nantinya akan berguna bagi hidupanya, selain yang didapat mereka dari sekolah formal. Mereka harus dibimbing dan dilatih untuk menyadari bahwa mereka tidak selamanya akan hidup dipanti asuhan, mereka akan keluar dari panti dan hidup pada lingkungan masyarakat yang heterogen (Badan Kesejahteraan Sosial Nasional). Selama ini panti asuhan rumah yatim Arrohman hanya menyediakan sarana tempat tinggal sedangkan untuk sekolah formal anak-anak panti bersekolah diluar dari panti. Sementara untuk pendidikan informal anak-anak panti hanya mendapatkan seperti mengaji, pesantren, olah raga. Untuk saat ini mereka belum pernah mendapatkan pelatihan dan bimbingan mengenai jahit menjahit dan membuat prakarya berbahan dasar perca. diharapkan dengan pelatihan ini mereka dapat membuka usaha menerima jahitan. Metode yang dikerjakan dalam kegiatan ini adalah dengan pelatihan dan bimbingan, dimana pelatihan dilakukan dengan praktek sebanyak $85 \%$ dan teori $15 \%$ selama enam bulan pelatihan. Diharapkan dapat menjadi sumbermata pencaharian bagi anak panti dikemudian akhir.
\end{abstract}

Kata kunci: Panti Asuhan; Rumah Yatim; Menjahit; kain perca

ABSTRACT. The problems of the Lampung branch of the Aarohman Orphanage are generally the same as other orphanages. First, the main problems found in children like younger siblings in this orphanage are insecurity and mental blocking, that they are poor people and can't be as successful as others. This perception can make children fail in competition with the outside world. Secondly, orphans now only have formal education, which still lacks skills. Technical skills that can be equipped for orphans to meet future life needs. For example, sewing skills and making patchwork fabric. given and guided motivation to learn something that will later be useful for their lives, in addition to what they get from formal schooling. They must be guided and trained to realize that they will not always live in an orphanage, they will leave the orphanage and live in a heterogeneous community environment (National Social Welfare Agency). During this time the orphanage Arrohman orphanage only provides housing facilities while for formal schools the orphans attend school outside of the orphanage. Meanwhile, for informal education, the orphans only get lessons such as the Koran, Islamic boarding schools, sports. At present, they have never received training and guidance on sewing, and making patchwork-based crafts or material perca. It is hoped that with this training they can open a business receiving stitches. The method used in this activity is by training and guidance, where training is carried out with $85 \%$ practice and $15 \%$ theory for six months of training. It is expected to be a source of livelihood for orphans in the later years.

Key words: Orphanage; Rumah Yatim; Sew; patchwork

\section{PENDAHULUAN}

Panti asuhan adalah suatu lembaga pelayanan sosial yang didirikan oleh pemerintah maupun masyarakat, yang bertujuan untuk membantu atau memberikan bantuan terhadap individu, kelompok masyarakat dalam upaya memenuhi kebutuhan hidup (Bardawi Barzan:1999: 5). Lebih lanjut Depsos RI (2004:4) menjelaskan Panti Sosial Asuhan anak adalah suatu lembaga usaha kesejahteraan sosial yang mempunyai tanggung jawab untuk memberikan pelayanan kesejahteraan sosial pada anak telantar dengan melaksanakan penyantunan dan pengentasan anak telantar, memberikan pelayanan pengganti orang tua/wali anak dalam memenuhi kebutuhan fisik, mental dan sosial kepada anak asuh sehingga memperoleh kesempatan yang luas,tepat dan memadai bagi pengembangan kepribadianya sesuai dengan yang diharapkan sebagai bagian dari generasi penerus cita- cita bangsa dan sebagai insan yang akan turut serta aktif dalam bidang pembangunan nasional. Tujuan panti asuhan itu sendiri adalah, memberikan pelayanan yang berdasarkan pada profesi pekerja sosial kepada anak terlantar dengan cara membantu dan membimbingan mereka ke arah perkembangan pribadi yang wajar serta mempunyai keterampilan kerja, sehingga mereka menjadi anggota masyarakat yang dapat hidup layak dan penuh tanggung jawab, baik terhadap dirinya, keluarga dan masyarakat (Depsos, 1997). Oleh karenanya salah satu fungsi Panti asuhan adalah sebagai pusat pengembangan keterampilan (yang merupakan fungsi penunjang).

Peningkatan sumber daya manusia merupakan hal yang penting bagi kemajuan suatu bangsa, setiap individu berhak untuk memperoleh pendidikan maupun keterampilan sesuai dengan kategori umur tidak terkecuali 
anak-anak yang berada dalam suatu wadah penampungan yang disebut Panti Asuhan. Pelaksanaan pengasuhan dalam panti asuhan bukan saja kewajiban dari pihak Panti Asuhan, melainkan juga tanggungjawab dari pemerintah, pihak swasta yang memiliki kompetensi dan profesi pekerjaan sosial.(Depsos,1997).

Persoalan utama yang ditemukan pada anak-anak seperti adik-adik di panti asuhan ini adalah rasa minder dan adanya mental blocking, bahwa mereka anak adalah orang yang malang dan tidak bisa sesukses seperti orang lain, oleh sebab itu, merubah cara pandang mereka adalah langkah yang paling mendasar dan sangat diperlukan oleh anak-anak panti asuhan. Masalah kedua adalah kurangnya pendidikan keterampilan yang bisa menjadi jalan mereka untuk meraih sukses kedepannya. Pada umumnya mereka hanya dibekali oleh pengetahuan formal yang genaral dibangku sekolahan. Berdasarkan dari pemikiran dan pedoman-pedoman tersebut diatas maka kami akademisi merasa ikut bertanggungjawab untuk menjadi volunteer dan donator individu, melakukan dan memberikan pelatihan atau yang sifatnya tidak permanen.

Mitra pada pengabdian adalah Rumah Yatim Arrohman Indonesia Lampung, khusus asrama putri yang beralamat di Jl. Teluk Diponegoro No. 74 Teluk Betung utara dan sekarang pindah ke Jl. Wolter Monginsidi No. 45 Tanjung Karang Pusat, bandar lampung.

Berdasarkan survey dan analisis situasi yang dilakukan pada Panti Asuhan Rumah Yatim Putri Arrahaman. Masalah yang di hadapi adalah pertama yang ditemukan pada anak anak seperti adik-adik di panti asuhan ini adalah rasa minder dan adanya mental blocking,bahwa mereka adalah orang yang malang dan tidak bisa sesukses seperti orang lain. Hal ini dilihat dari ketika mereka di ajak oleh tim kami untuk diskusi interaktif tentang kemampuan keterampilan dan sosialisasi kemasyarakat banyak anak yang malu untuk mengutarakan keinginan mengembangkan menjahit mereka, padahal kemampuan dasar menjahit anak panti asuhan sudah dimiliki sehingga perlu dilakukan peningkatan agar anak-anak lebih percaya diri dengan cara meningkatkan kreatifitas keterampilan menjahit mereka,mereka diberikan motivasi belajar dan pengenalan moral yang bisa digunakan ketika mereka telah memiliki keterampilan menjahit mereka bisa dengan baik menerapkan keterampilan mereka dan memberikan ide-ide kreatif atas pengembangan jahit mereka.hal ini berdampak pada peningkatan kualitas keterampilan anak dan sosialisasi dikalangan masyarakat bahwa mereka anakanak panti bisa memiliki keterampilan dan meningkatkan pendapatan mereka serta peningkatan pada hubungan social kepada masyarakat secara luas.

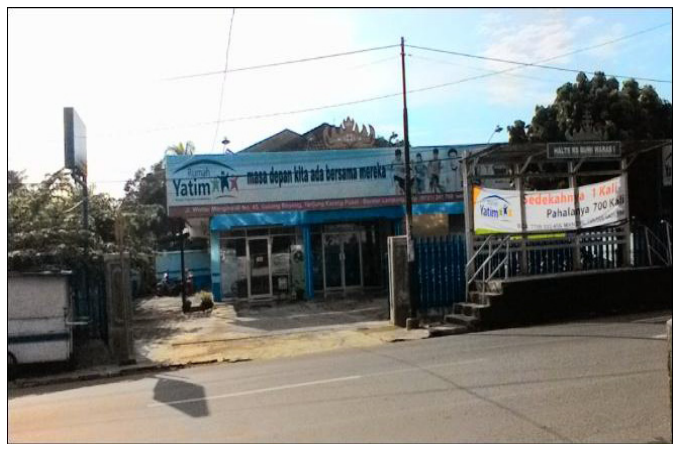

\section{Gambar 1. Foto Lokasi Mitra IbM}

Persepsi ini dapat membuat anak gagal dalam berkompetisi dengan dunia luar. Kedua, Anak Yatim saat ini hanya mengenyam pendidikan Formal, yang masih minim mengajarkan keterampilan. Keterampilan tehnis yang bisa menjadi bekal anak yatim dalam pencukupi kebutuhan hidup kedepannya. Misalnya keterampilan menjahit dan membuat pelengkapan berbahan perca kain. Sehingga Pengabdian ini sangat urgen untuk dilaksanakan.

\section{METODE}

Dari permasalahan yang dihadapi mitra, maka solusi yang ditawarkan akan menggunakan metode pelatihan dan kursus dengan teknik interaktif. Sehingga materi lebih banyak ke praktik Langsung (85\%) dan teori (15\%.) Dalam pelatihan ini (Ketua dan Anggota Tim Pengabdian) Akan dibantu oleh dua mahasiswa yang pandai menjahit dan satu mahasiswa yang pandai membuat desain kreatif ecommerce. Adapun Rincian materi pelatihan adalah sebagai berikut:

Tabel 1. Solusi yang Ditawarkan

\begin{tabular}{|c|c|c|c|}
\hline Masalah & Permasalahan & Tujuan & $\begin{array}{c}\text { Solusi yang ditawarkan } \\
\text { (Metode) }\end{array}$ \\
\hline $\begin{array}{l}\text { Mental dan kepribadian anak } \\
\text { Yatim Piatu }\end{array}$ & $\begin{array}{l}\text { Rendahnya rasa percaya diri } \\
\text { anak Yatim Piatu di kedua mitra, } \\
\text { yang menyebabkan mereka } \\
\text { cenderung minder dan rendah } \\
\text { diri }\end{array}$ & $\begin{array}{l}\text { Meningkatkan rasa percaya } \\
\text { diri dan kepribadian anak } \\
\text { yatim piatu, agar mereka bisa } \\
\text { bersaing kedepannya }\end{array}$ & Pelatihan charakter building \\
\hline $\begin{array}{l}\text { Minimnya perolehan materi } \\
\text { keterampilan menjahit } \\
\text { untuk menjadi sumber mata } \\
\text { pencaharian }\end{array}$ & $\begin{array}{l}\text { Rendahnya keterampilan jahit } \\
\text { menjahit anak panti asuhan }\end{array}$ & $\begin{array}{l}\text { Meningkatkan pengetahuan } \\
\text { dan keterampilan anak yatim } \\
\text { piatu terkait denganjahit } \\
\text { menjahit }\end{array}$ & $\begin{array}{l}\text { Pelatihan konsep dasar jahit } \\
\text { menjahit, pembuatan pola, } \\
\text { dan membuat pakaian yang } \\
\text { siap untuk dijual }\end{array}$ \\
\hline $\begin{array}{l}\text { Minimnya keterampilan } \\
\text { pembuatan prakarya berbahan } \\
\text { dasar perca }\end{array}$ & $\begin{array}{l}\text { Rendahnya keterampilan } \\
\text { pembuatan prakarya berbahan } \\
\text { dasar perca }\end{array}$ & $\begin{array}{l}\text { Meningkatkan pengetahuan } \\
\text { dan keterampilan anak } \\
\text { yatim piatu terkait dengan } \\
\text { pembuatan prakarya } \\
\text { berbahan dasar perca }\end{array}$ & $\begin{array}{l}\text { Pelatihan pembuatan } \\
\text { prakarya berbahan dasar } \\
\text { perca, misalnya bros, keset } \\
\text { kaki, lampin, tempat tisu dll } \\
\text { yang siap jual }\end{array}$ \\
\hline
\end{tabular}




\section{HASIL DAN PEMBAHASAN}

Program pengabdian di Panti Asuhan Rumah Yatim Arrohman ditargetkan agar anak-anak Panti Asuhan dapat memiliki mental yang baik dan tidak minder, memiliki keahlian di bidang Jahit Menjahit, dimana kedepannya sebagai bekal hidup mereka. Untuk target dari pengabdian ini dapat kami jelaskan sebagai berikut:

1. Pelatihan Character Building, selama 1 bulan pertama kami melakukan kegiatan dengan cara melakukan diskusi interaktif langsung ke anak-anak memberikan motivasi pada anak-anak untuk bisa lebih percaya diri lagi, menanamkan nilai-nilai moral yang menjadikan pegangan mereka untuk kedepannya serta menjadikan kemampuan keterampilan menjahit mereka sebagai penambahan pendapatan dan ilmu pengetahuan dimasa depan nanti. Dampak yang dirasakan misalnya anak-anak Yatim Piatu tidak minder lagi dan memiliki kepercayaan yang tinggi dalam bergaul dan mencari teman.

2. Selama tiga bulan pertama kami menargetkan 3 anak Panti Asuhan dari Panti Asuhan Rumah Yatim Arohman, (Anak perempuan usia 15 tahun keatas), dapat pengenalan dunia jahit menjahit, bisa mengoperasikan mesin jahit dan mendesain pola kain jahitan

3. Selama tiga bulan kedua sebanyak 10 orang anak Panti Asuhan dapat mengoperasikan mesin jahit dengan lancar, mampu membuat pola pakaian pada kertas pola dan mampu membuat contoh jahitan sederhana

4. Pada 2 bulan berikut dalam pengabdian ini, masingmasing anak dibantu atau dibimbing dan diberi untuk menjahit dengan model yang lebih rumit. Misalnya mampu membuat pakaian sekolah sendiri.

5. Pada 1 bulan berikut dalam pengabdian ini, masingmasing anak dibantu atau dibimbing dan diberi untuk menjahit dengan berbahan kain perca. Misalnya mampu membuat bros, tutup toples, keset, tempat tisu dan lain berbahan kain perca. Contoh produk sebagai berikut:
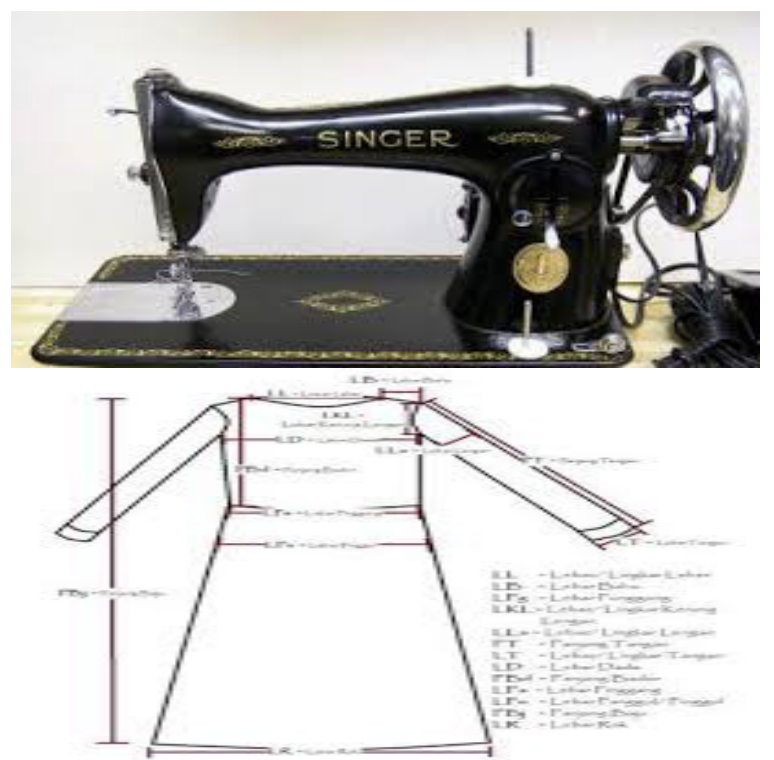

Gambar 2. Kemampuan menggunakan mesin jahit dan membuat pola jahitan

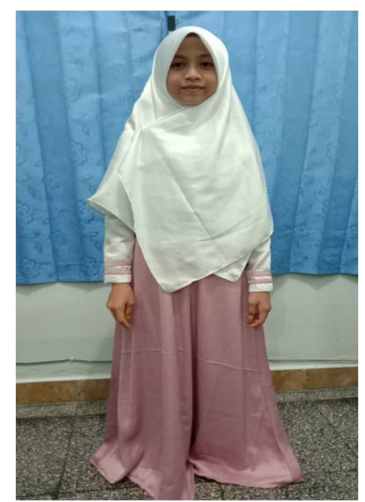

Gambar 3. Pembuatan Baju hasil jahit anak-anak panti

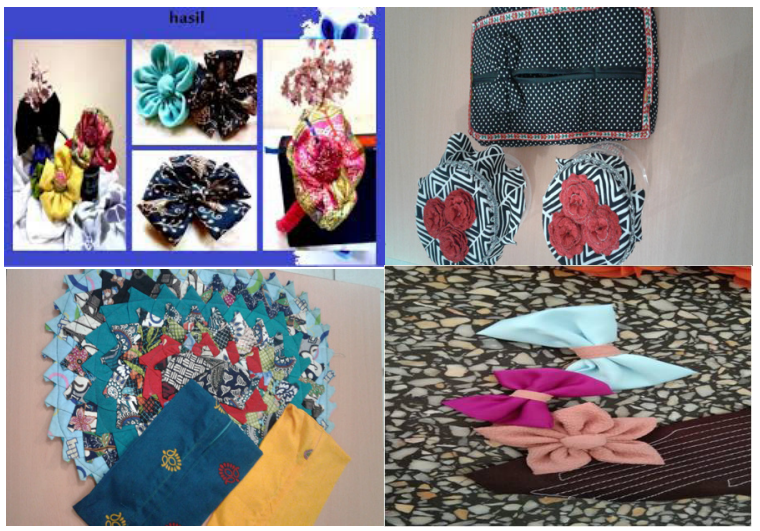

Gambar 4. Pembuatan Bros, tempat tisu, tutup toples dan Keset Kaki dari Kain Perca

Pembahasan dari pengabdian pada panti asuhan ini adalah berupa:

1. Anak-anak yatim piatu tidak minder lagi dan memiliki kepercayaan tinggi dalam bergaul dan mencari penghasilan dengan teman-teman sebaya yang lain.

2. Kemampuan anak-anak yatim piatu untuk menjahit dan mendesain pola jahitan semakin meningkat, dan produk yang dihasilakan dapat bersaing dengan produk dipasaran.

3. Anak-anak yatim piatu mampu membuat keterampilan berbahan dasar perca dengan kualitas yang mampu dipasarkan. Sehingga dapat menjadi bahan mata pencaharian baru. Contohnya mampu membuat Bros, Keset Kaki, tutup toples, Tempat tisu dan sebagainya.

\section{SIMPULAN}

Dari pengabdian ini ditarik kesimpulan bahwa dengan Pengembangan Keterampilan Menjahit Bagi Anak Panti Asuhan Di Kota Bandar Lampung. diharapkan dapat meningkatkan kualitas anak-anak panti dalam menyiakan diri didunia kerja dengan kemampuan lebih dibidang keterampilan khususnya menjahit dan mampu mendorong keinginan anak-anak panti untuk turut mengembangkan diri bahkan memunculkan ide-ide baru yang lebih baik. Pelatihan pengembangan keterampilan menjahit bagi anak panti dapat membantu meningkatkan kualitas dan motivasi 
kepercayaan diri anak-anak panti. Pada serangkaian kegiatan Pengembangan Keterampilan Menjahit Bagi Anak Panti Asuhan rumah yatim digunakan sebagai media peningkatan kualitas dan motivasi anak-anak panti sebagai informasi yang dapat di rasakan manfaatnya secara luas untuk masa depan.

\section{UCAPAN TERIMAKASIH}

Kami ingin menyampaikan terima kasih kepada Kementerian Riset dan Teknologi Tinggi Pendidikan di Jakarta untuk membiayai pengabdian ini. Selanjutnya, kami juga berterima kasih kepada lembaga penelitian dan pengembangan pembelajaran dan pengabdian masyarakat di Informatika dan Bisnis Darmajaya, Bandar Lampung. Kami juga berterima kasih kepada kolega yang telah mendukung kami sehingga artikel pengabdian ini dapat diselesaikan serta mengucapkan terima kasih kepada Tim Redaksi Jurnal Pengabdian Kepada Masyarakat "Dharmakarya" oleh Direktorat Sumber Daya Akademik Universitas Padjadjaran yang telah memberi kesempatan, sehingga artikel pengabdian ini dapat diterbitkan.

\section{DAFTAR PUSTAKA}

Aisyah, T. N., \& Novitasari, D. (2016). Kencana: Kerajinan Kain Perca Menjadi Line Art sebagai Industri Kreatif Berpeluang Ekonomi. Pena: Jurnal Penelitian Dan Penalaran, 3(1), 463-470.
Rambe, A. (2015). IbM Usaha Penjahit Busana Wanita dalam Pembuatan Aksesoris dari Limbah Kain Perca. Jurnal Pengabdian Kepada Masyarakat, 21(82), 1-6.

Sucipto, N. R., \& Sutarto, J. (2015). Pemberdayaan Masyarakat Miskin untuk Meningkatkan Kecakapan Hidup Melalui Kursus Menjahit di LKP Elisa Tegal. Journal of Nonformal Education and Community Empowerment, 4(2).

Wardiani, S. R., Intan, T., \& Subekti, M. (2018). Pemberdayaan Ibu Rumah Tangga Dalam Upaya Peningkatan Ekonomi Keluarga Di Desa Rancamulya Dan Tambak Jati Kecamatan Patok Beusi-Subang. Dharmakarya, 7(4), 221227.

Pelaksanaan pengasuhan dalam panti asuhan bukan saja kewajiban dari pihak Panti Asuhan, melainkan juga tanggungjawab dari pemerintah, pihak swasta yang memiliki kompetensi dan profesi pekerjaan sosial.(Depsos,1997).

Barzan. B. (1999). Panti Asuhan sebagai Lingkungan Keluarga. Yogyakarta: Rineka Cipta

https://bulelengkab.go.id/detail/artikel/lembagakesejahteraan-sosial-anak-lksa-93 